OPEN ACCESS

Edited by:

Yiqiu Tan,

Harbin Institute of Technology, China

Reviewed by:

Ramadhansyah Putra Jaya, Universiti Malaysia Pahang, Malaysia

$\mathrm{Ru} \mathrm{Mu}$,

Hebei University of Technology, China

*Correspondence:

Wenke Huang

wukuanghuai@163.com

Kuanghuai Wu

hwk_gzu@163.com

Specialty section:

This article was submitted to Structural Materials,

a section of the journal

Frontiers in Materials

Received: 26 December 2019

Accepted: 25 March 2020

Published: 30 April 2020

Citation:

Cai X, Huang W, Liang J and Wu K (2020) Study of Pavement

Performance of Thin-Coat

Waterborne Epoxy Emulsified Asphalt

Mixture. Front. Mater. 7:88.

doi: 10.3389/fmats.2020.00088

\section{Study of Pavement Performance of Thin-Coat Waterborne Epoxy Emulsified Asphalt Mixture}

\author{
Xu Cai, Wenke Huang*, Juan Liang and Kuanghuai Wu* \\ School of Civil Engineering, Guangzhou University, Guangzhou, China
}

Waterborne epoxy emulsified asphalts (WEEA) have high densities, good chemical stabilities, and high viscosities. However, they have problems in terms of overly high stiffness and low-temperature brittleness when applied as thin-coat asphalt mixtures. In this study, testing was conducted to obtain the optimal mixing ratio for WEEA. Anti-sliding, rutting, water stability, Cantabro, and low-temperature bending tests were carried out to evaluate the performance of thin coating layers formed from open graded friction course (OGFC)-5 WEEA mixtures, with the results indicating that the optimal ratio of waterborne epoxy resin emulsion and curing agent was 2:1 and that the dosage of waterborne epoxy resin should be maintained between 15 and 30\%. The surface texture depth and British Pendulum Number (BPN) of the OGFC-5 WEEA mixtures were larger than $0.91 \mathrm{~mm}$ and 77.4 , respectively, and the WEEA mixtures had better water stabilities and spalling resistance performance than a mixture without WEEA. Waterborne epoxy resin dosages of 15 and 30\% resulted in WEEA mixture stabilities of up to 4,285 and 8,798 times $/ \mathrm{mm}$, respectively, and tensile strengths at $-10^{\circ} \mathrm{C}$ of 2.204 and $4.727 \mathrm{MPa}$, respectively. The relatively good pavement functional and low-temperature performance of the optimized OGFC-5 WEEA mixture suggest its usefulness as a pavement maintenance material.

\section{Keywords: waterborne epoxy resin, emulsified asphalt mixture, thin-layer coating, open-graded friction course, road performance}

\section{INTRODUCTION}

Maintenance of the enormous and growing highway network system in China is becoming increasingly challenging. Cracks, ruts, pits, and asphalt pavement spalling affect traffic safety and reduce the service life of the pavement (Christina, 2019; Wu et al., 2019). It has been found that the application of emulsified asphalt is an effective method of pavement maintenance that is compatible with current developmental trends in asphalt pavement technology (Anthonissen et al., 2016; Law et al., 2017; Santos et al., 2018). Compared with hot mix asphalt, an emulsified asphalt mixture has many advantages for use as a construction material, including improving the construction environment, reducing the effects of environmental factors, saving energy, etc., and has therefore come to be widely used in preventive and daily pavement maintenance. However, the use of emulsified asphalt as a cementing material has a number of disadvantages, including low strength in the early stages of setting, insufficient cohesion, and poor water and temperature stability (Wang, 2015), all of which have restricted the popularization and application of emulsified asphalt. 
Based on the performance of cold-mix asphalts before curing, a number of studies have focused on their use in strengthening the performance of asphalts. Some researchers have looked at cement as an additive and carried out indirect tensile, repeated load asphalt creep, and water damage tests to evaluate the performance of cold-mix asphalt mixtures in cement powder. The results of these assessments revealed that cement-modified emulsion mixtures often outperformed hot-mix asphalts (Oruc et al., 2006, 2007). Wang et al. (2015) evaluated various properties of fresh cement-emulsified asphalt mortar and found that increasing the asphalt/cement ratio significantly reduced the compressive strength of the mortar. A further investigation of the properties of cement-stabilized gravel modified by emulsified asphalt (Wang et al., 2017) revealed that cement-emulsified asphalt-stabilized gravel with $5 \mathrm{wt} \%$ cement performed well both mechanically and in terms of frost resistance. And some recent studies show that surfactants also have a good effect on increasing the strength of cement asphalt emulsion mixture (Ouyang et al., 2018, 2019; Yang et al., 2020). Other researchers have looked at the use of styrene-butadiene rubber (SBR), styrenebutylene-styrene (SBS), chloroprene rubber (CR), and other polymers to prepare modified emulsified asphalt. Compared with ordinary emulsified asphalt, the high-temperature rheological properties of the modified emulsified asphalts were slightly improved, but the low-temperature properties were essentially the same (Pan et al., 2015). Shafii et al. (2011) found that SBS-modified emulsified asphalt had better high- and lowtemperature performance than other types of modified asphalt. To improve the compressive strength of cold-mix asphalt, Chávez-Valencia et al. (2007) added a polyvinyl acetate emulsion to emulsified asphalt and found that the compressive strengths of the test specimens were improved by $31 \%$ compared to that of an unmodified mixture. Because the performance of an asphalt mixture is strongly influenced by the physical and chemical properties of the minerals and binders used in the mixture, the adherence between minerals and binders has been extensively studied, with surface free energy used to calculate the amounts of adsorbed vapor corresponding to monolayer occupancy on the surfaces of materials with different additives. The results of these experiments have shown that the wet-condition adhesive bond strengths of binders with various mineral/aggregate combinations are improved through the use of additives (Khan et al., 2016). Kim et al. (2019) experimentally evaluated the short- and long-term performance of SBS-modified asphalt binder added to ground tire rubber and styrene-isoprene-styrene and found that the addition of styreneisoprene-styrene can significantly improve rutting performances. Hamed et al. (2019) investigated the moisture susceptibility of emulsified asphalt treated with microbial carbonate precipitation, finding that the treatment significantly improved the moisture resistance of the mixture. Jiang et al. (2020) investigated the properties of asphalt binder in terms of the rutting of the cold recycling mix, with their results indicating that hightemperature performance could be improved significantly by adding polymer modifiers and that adding CR latex appeared to be a more effective method for improving the rutting resistance of emulsified asphalt.
The results of these previous lab studies indicate that the performance of SBS-modified emulsified asphalt that has been formed and cured is better than that of ordinary emulsified asphalt. However, the addition of polymers to emulsified asphalt does not appear to fundamentally change the characteristics of the emulsified asphalt. Some studies have also mentioned the difficulty of preparing emulsified asphalt mixtures and the necessity of further improving the stability of the materials. In practical applications, the shortcomings of the slow strength formation and the insufficient bonding of such mixtures with pavement have not been fully overcome. Furthermore, such mixtures are not suitable for use in damp environments. To overcome these problems, some researchers have explored the use of waterborne epoxy resin. Waterborne epoxy emulsified asphalts (WEEAs) produced by modification by water-based epoxy resins can be cured in damp conditions and at room temperature and have proven to have high densities, good chemical stabilities, and high viscosities (Yu, 2018). To obtain binding materials with high bonding strengths at high temperatures and high flexibilities at low temperatures, several WEEA preparation methods have been explored, with the resulting WEEAs exhibiting excellent bonding strength, crack resistance, and anti-impact properties and, depending on the preparation procedure, high water stability and the ability to adhere to aggregates (Yang et al., 2019). WEEA mixtures with aluminum trihydroxide and zinc borate as additives have been used in tunnel construction (Chen et al., 2018). Given the insufficient durabilities of conventional preventive maintenance techniques using bitumen emulsions, some researchers have investigated the performance of WEEA as a pavement preventive maintenance material, with the results indicating that the waterborne epoxy distributes evenly within the asphalt matrix, and significantly improves the skid resistance and durability of pavements maintained with asphalt emulsion coating layers (Hu et al., 2019). In the other research, WEEA mixtures have been used as permeating and solidifying seal coat materials in what could be considered a new generation of preventive maintenance treatments for asphalt pavements (Liang et al., 2019). It has been found that the technical compatibility of cured WEEA mixture is enhanced as the waterborne epoxy content increases over content ranges below 30\% (Gu et al., 2019).

Despite the achievements in the research on WEEA mixtures, their application as thin-coat layers remain in the early stages. The shortcomings of the overly high stiffness and brittleness introduced by the waterborne epoxy resin remain to be solved. In practical engineering applications, high levels of stiffness result in enhanced stress on materials under heavy traffic conditions. Furthermore, the lack of thickness of thin-coat WEEA mixtures (which are generally less than $2 \mathrm{~cm}$ in depth) makes the material more prone to cracking in winter. To examine the low-temperature durability of thin-coat WEEA mixtures under heavy traffic loads, in this study a WEEA mixture with high strength, good bonding performance, high stability, and reduced brittleness for use as a thin-coating layer for pavement maintenance material was developed. 


\section{MATERIALS AND METHODS}

\section{Materials \\ Emulsified Asphalt}

The emulsified asphalt used in this experiment was an SBSmodified emulsified asphalt produced by Jiangmen Qiangda Highway Materials Co., LTD. The sample was a dark brown liquid. All technical indices of the material were tested following the Standard Test Methods of Bitumen and Mixtures for Highway Engineering (JTG E20-2011), with the results listed in Table 1.

\section{Waterborne Epoxy Emulsion and Curing Agent}

The water-borne epoxy resin emulsion and curing agent used in the experiments (Shanxi Xinhua Chemical Co. LTD) could be stored stably at $-5-40^{\circ} \mathrm{C}$. The curing agent was a non-ionic water-soluble epoxy that contained no free surfactants and had a good compatibility with water-based epoxy resin. The agent could be cured at room temperature and directly diluted with water. The technical parameters of the waterborne epoxy resin emulsion and curing agent are listed in Table 2.

\section{Aggregates and Cement}

Diabase aggregates were used in the experiment, with all technical parameters tested using the Test Methods of Aggregate for Highway Engineering (2005; JTG E42-2005). Limestone powder was used in conjunction with Portland P.O42.5 cement. The results are listed in Table 3.

\section{Mixture Gradation}

In consideration of the emulsifying environment requirements of emulsified asphalt, an open graded friction course (OGFC)5 mixture with a $5.2 \%$ asphalt-aggregate ratio was used in the experiment. A designed void of $22 \%$ was used to obtain better conditions for demulsifying. The gradation is indicated in Table 4.

\section{Test Methods}

\section{Asphalt Performance Tests}

To test the asphalt performance, waterborne-epoxy-resin-tocuring-agent mass ratios of 2:1, 1:1, and 1:2, with the proportion of water-borne epoxy content in the emulsified asphalt ranging from 5 to $10,15,20,25$, and $30 \%$, were used. The WEEAs were prepared using the following cold mixing process: (1) the waterbased epoxy resin emulsion was added to the emulsified asphalt, and the mix was stirred for $5 \mathrm{~s}$; (2) the curing agent was then added and the mix was stirred again for $3 \mathrm{~min}$. The performances of the respective WEEAs were studied using fluorescence microscopy, adhesion, and evaporation residue tests.

\section{Particle Dispersion State Observation}

A fluorescence microscope uses a color-filtering system to produce a specific wavelength of light to evaluate the uniformity of materials (Johann and Juergen, 2004). By using a fluorescence microscope, the particle size and dispersion state of waterborne epoxy resin in emulsified asphalt can be observed along with the micro-morphology of the resin and asphalt mixture. In this study, three samples were prepared for each mixture ratio. Each asphalt sample has an area of $30 \mathrm{~mm}^{2}$ and an asphalt film thickness of $0.1 \mathrm{~mm}$, as shown in Figure 1. The magnification of the fluorescence microscope was set to $400 \times$.

\section{Boiling Water Test}

Boiling tests were carried out at $60^{\circ} \mathrm{C}$ using the Standard Test Methods of Bitumen and Mixtures for Highway Engineering (JTG E20-2011). The maximum nominal particle size of the aggregates used in the tests was $9.5 \mathrm{~mm}$. Three specimens of each WEEA and one control sample without waterborne epoxy resin were tested.

\section{Properties of Evaporative Residue}

The effects of the waterborne epoxy resin emulsions added to the emulsified asphalts on the evaporative residual properties of the WEEAs were evaluated via penetration, softening point, and ductility testing.

\section{Asphalt Mixture Performance Tests}

Based on the results of Marshall testing, the asphalt-aggregate ratio was set to $5.2 \%$. Water-borne epoxy dosages of 0,15 , and $30 \%$ were added, and $3 \%$ cement was used. The following mixture-forming steps were adopted: (1) 25 Marshall doublesided compactions were applied to preliminarily mold the specimens; (2) the specimens and molds were placed vertically in a $60^{\circ} \mathrm{C}$ oven for $12 \mathrm{~h}$, and then another 25 Marshall doublesided compactions were applied; and (3) After demolding, the specimens were placed in a $60^{\circ} \mathrm{C}$ oven for $36 \mathrm{~h}$. After returning the specimens to the test temperature, follow-up tests were conducted. A similar process was used to obtain rutting specimens.

\section{Anti-sliding Performance Test}

The British Pendulum Number (BPN) was used as a measure of the skid resistance of the pavements. Pendulum testing was carried out using Procedure T0964 of the Field Test Method of Subgrade and Pavement for Highway Engineering (2008; JTG E60-2008). As shown in Figure 2, three specimens were tested for each mixture.

The surface texture depths (TDs) of the asphalt mixture rutting specimens were measured using Procedure T0731 of the Standard Test Methods of Bitumen and Mixtures for Highway Engineering (2011). The TD results were calculated as follows:

$$
\mathrm{TD}=\frac{100 \times V}{\pi \times D^{2} / 4}=\frac{31831}{D^{2}},
$$

where $V$ is the volume of the standard test sand and $D$ is the average diameter of the flat sand.

\section{Rutting Tests}

The influence of the WEEA on the high-temperature stability of the mixtures was evaluated using rutting tests, with the dynamic stability index used to quantitatively evaluate rutting performance. Three specimens, each with dimensions of $300 \mathrm{~mm} \times 300 \mathrm{~mm} \times 50 \mathrm{~mm}$, were tested for each material, with the average value of the three taken as the test result for each material. A solid rubber wheel with an outer diameter of $200 \mathrm{~mm}$ 
TABLE 1 | Technical parameters of SBS-modified emulsified asphalt.

\begin{tabular}{|c|c|c|c|c|}
\hline Test & & Unit & Results & Method \\
\hline Residual amount & & $\%$ & 0.02 & T 0652 \\
\hline Charge & & - & Cationic & Т0653 \\
\hline Demulsification velocity & & - & Slow & T 0658 \\
\hline \multirow[t]{7}{*}{ Properties of evaporative residue of emulsified asphalt } & Asphalt content & $\%$ & 62.9 & T 0651 \\
\hline & Penetration at $25^{\circ} \mathrm{C}$ & $0.1 \mathrm{~mm}$ & 41 & T 0604 \\
\hline & Softening point & ${ }^{\circ} \mathrm{C}$ & 80.3 & T 0606 \\
\hline & Ductility at $5^{\circ} \mathrm{C}$ & $\mathrm{cm}$ & 56 & Т 0605 \\
\hline & Dynamic viscosity at $60^{\circ} \mathrm{C}$ & Pa's & 216,858 & Т 0620 \\
\hline & Rotary viscometer at $135^{\circ} \mathrm{C}$ & Pa's & 6.317 & T 0625 \\
\hline & Solubility & $\%$ & 99.02 & Т 0607 \\
\hline Elastic recovery at $25^{\circ} \mathrm{C}$ & & $\%$ & 98.4 & Т 0662 \\
\hline \multirow[t]{2}{*}{ Storage stability } & $1 d$ & $\%$ & 0.4 & Т 0656 \\
\hline & $5 d$ & $\%$ & 1.6 & \\
\hline
\end{tabular}

TABLE 2 | Technical parameters of waterborne epoxy emulsion and curing agent.

\begin{tabular}{|c|c|c|c|}
\hline Test & Unit & Waterborne epoxy emulsion & Curing agent \\
\hline Appearance & - & Milky white resin emulsion & Yellowish uniform fluid \\
\hline Solid content & $\%$ & $50 \pm 2$ & $50 \pm 2$ \\
\hline Solid component & $\%$ & $22-28$ & 20-32 \\
\hline Viscosity at $25^{\circ} \mathrm{C}$ & MPa's & $100-450$ & $>2,000$ \\
\hline $\mathrm{pH}$ & - & $2-7$ & $8-11$ \\
\hline Specific gravity & - & $1.01-1.08$ & $1.00-1.08$ \\
\hline
\end{tabular}

TABLE 3 | Technical parameters of aggregates.

\begin{tabular}{|c|c|c|c|c|c|}
\hline \multirow[t]{2}{*}{ Tests } & \multirow[t]{2}{*}{ Unit } & \multicolumn{3}{|c|}{ Aggregates size } & \multirow[t]{2}{*}{ Methods } \\
\hline & & $5-10 \mathrm{~mm}$ & $3-5 \mathrm{~mm}$ & $0-3 \mathrm{~mm}$ & \\
\hline Crushing value & $\%$ & 4.9 & 5.3 & - & Т 0316 \\
\hline Los Angeles abrasion value & $\%$ & 6.1 & 6.1 & - & Т 0317 \\
\hline Water absorption & $\%$ & 0.87 & 0.96 & - & Т 0307 \\
\hline Density & $\mathrm{g} / \mathrm{cm}^{3}$ & 2.93 & 2.92 & 2.93 & T 0304/T 0328 \\
\hline Sand equivalent & $\%$ & - & - & 87 & Т 0334 \\
\hline Methylene blue value & $\mathrm{g} / \mathrm{kg}$ & - & - & 14 & T 0349 \\
\hline
\end{tabular}

TABLE 4 | Gradation of OGFC-5.

\begin{tabular}{|c|c|c|c|c|c|c|c|c|}
\hline \multirow[t]{2}{*}{ Gradation } & \multicolumn{8}{|c|}{ Mass percentage of aggregate passing through the following sieve pores $(\mathrm{mm}) / \%$} \\
\hline & 9.5 & 4.75 & 2.36 & 1.18 & 0.6 & 0.3 & 0.15 & 0.075 \\
\hline OGFC-5 & 100 & 76.5 & 14.7 & 9.3 & 7.7 & 6.3 & 5.3 & 4.5 \\
\hline
\end{tabular}

and a width of $50 \mathrm{~mm}$ was used as a test wheel. During the testing, the contact pressure between the test wheel and the specimen was maintained at $0.7 \mathrm{MPa}$. The rolling speed of the test wheel was 42 times/min and the test temperature was $60^{\circ} \mathrm{C}$, as shown in Figure 3.

\section{Water Stability Tests}

Water stability testing was carried out using Procedure T0709 of the Standard Test Methods of Bitumen and Mixtures for Highway Engineering (JTG E20-2011). Twelve Marshall specimens were formed and divided into two groups, one of which was immersed in a constant temperature bath at $60^{\circ} \mathrm{C}$ for $30 \mathrm{~min}$, while the other was immersed in a constant temperature bath at $60^{\circ} \mathrm{C}$ for $48 \mathrm{~h}$. The ratio of the average Marshall stabilities of the respective groups was used to evaluate the water stabilities of the mixtures.

\section{Cantabro Tests}

The adhesion properties of the asphalt and aggregate in each WEEA mixture were evaluated using the Cantabro test, with the results expressed as the percentage of mass lost by the Marshall specimens after a specified number of rotary hits using a Los Angeles test machine. Four specimens were evaluated for 


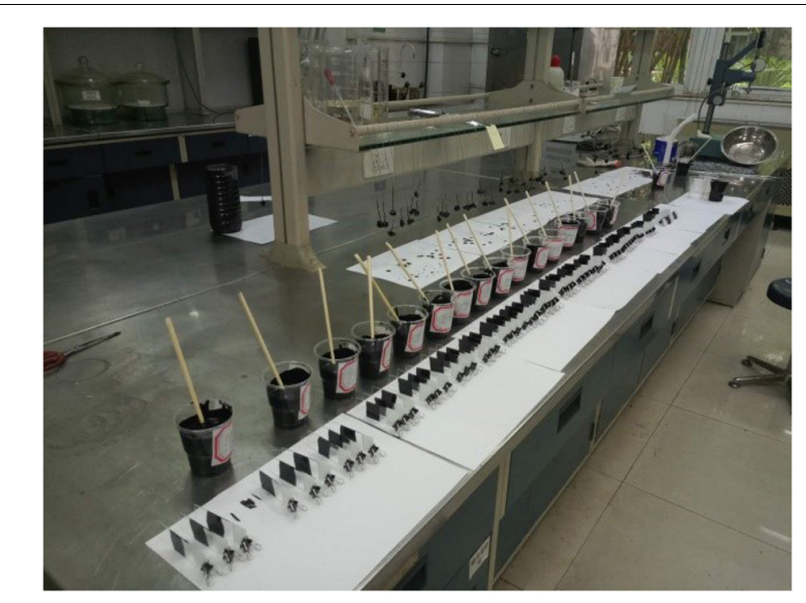

FIGURE 1 | Samples for particle dispersion state observation.

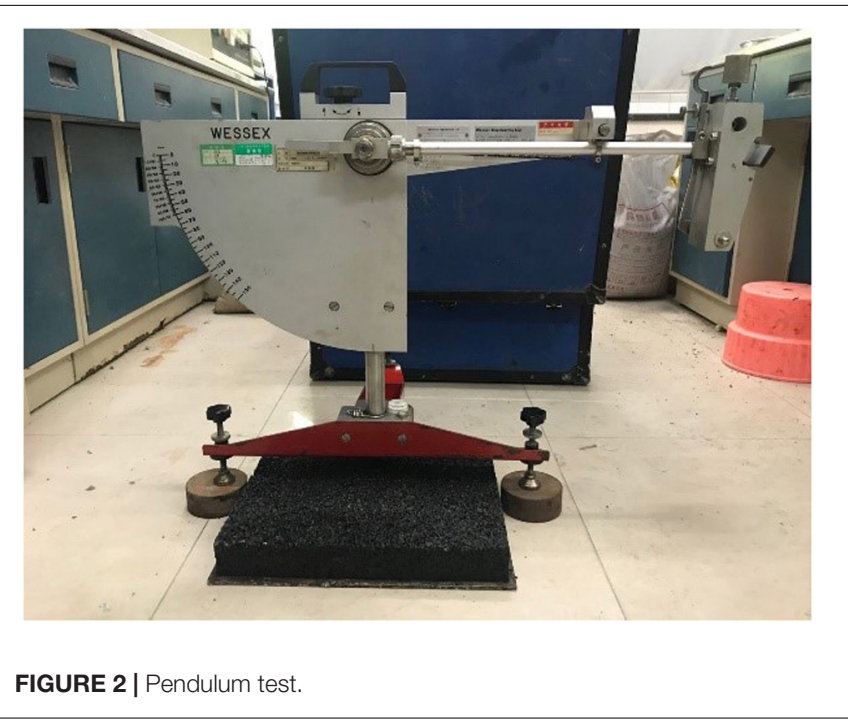

each material, with the average value taken as the test result for each material.

\section{Low-Temperature Bending Tests}

Low-temperature bending test were carried out using Procedure T0709 of the Standard Test Methods of Bitumen and Mixtures for Highway Engineering (JTG E20-2011). Each specimen had the dimensions $250 \mathrm{~mm} \pm 2.0 \mathrm{~mm}(\mathrm{l}) \times 30 \mathrm{~mm} \pm 2.0 \mathrm{~mm}(\mathrm{w})$ $\times 35 \mathrm{~mm} \pm 2.0 \mathrm{~mm}(\mathrm{~h})$. The specimens are shown in Figure 4. Testing was carried out at $0 \pm 0.5^{\circ} \mathrm{C}$ and $-10 \pm 0.5^{\circ} \mathrm{C}$ at a loading rate of $1 \mathrm{~mm} / \mathrm{min}$. For each material, five specimens were fabricated.

The flexural tensile strength $R_{B}$, maximum flexural tensile strain $\varepsilon_{B}$ at the beam bottom, and flexural stiffness modulus $s_{B}$ at failure were calculated as follows:

$$
R_{B}=\frac{3 \times L \times P_{B}}{2 \times b \times h^{2}},
$$

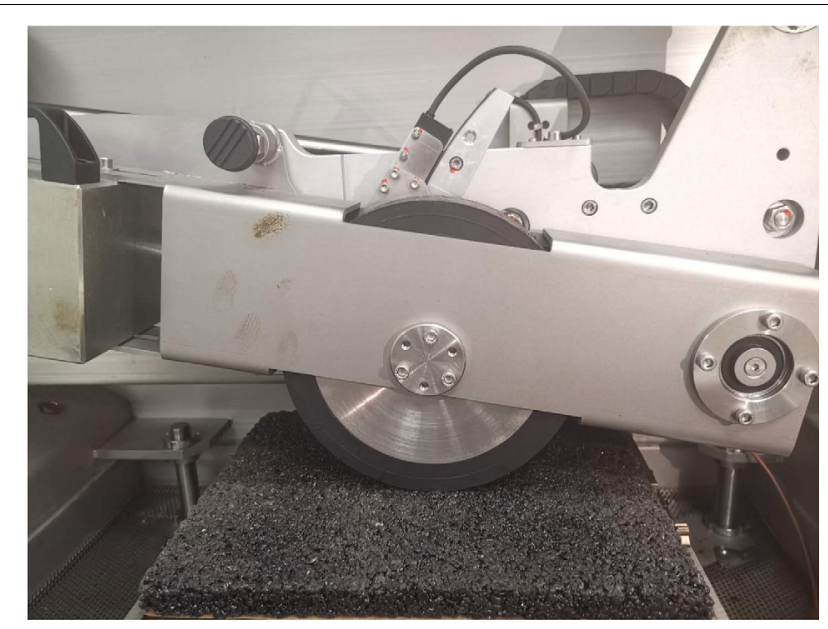

FIGURE 3 | Rutting tests.

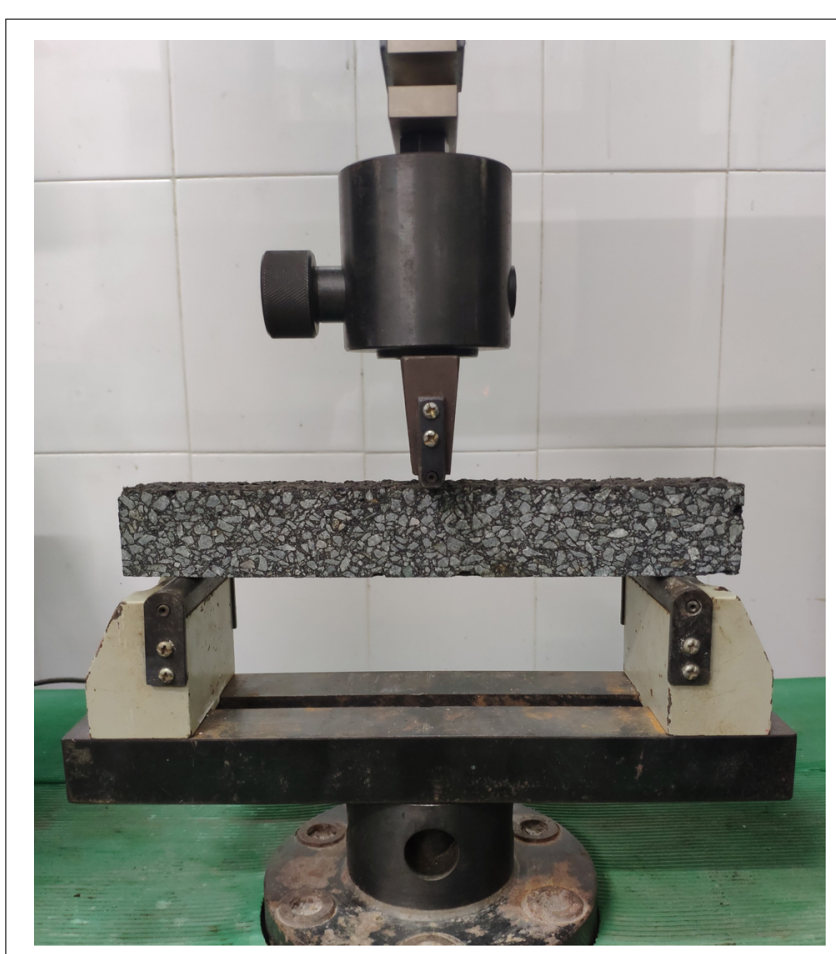

FIGURE 4 | Bending test.

$$
\begin{gathered}
\varepsilon_{B}=\frac{6 \times h \times d}{L^{2}}, \\
s_{B}=\frac{R_{B}}{\varepsilon_{B}},
\end{gathered}
$$

where $b, h$, and $L$ are, respectively, the width, height, and length of the specimen, $P_{B}$ is the maximum load at the time of failure, and $\mathrm{d}$ is the mid-span deflection at the time of failure. 


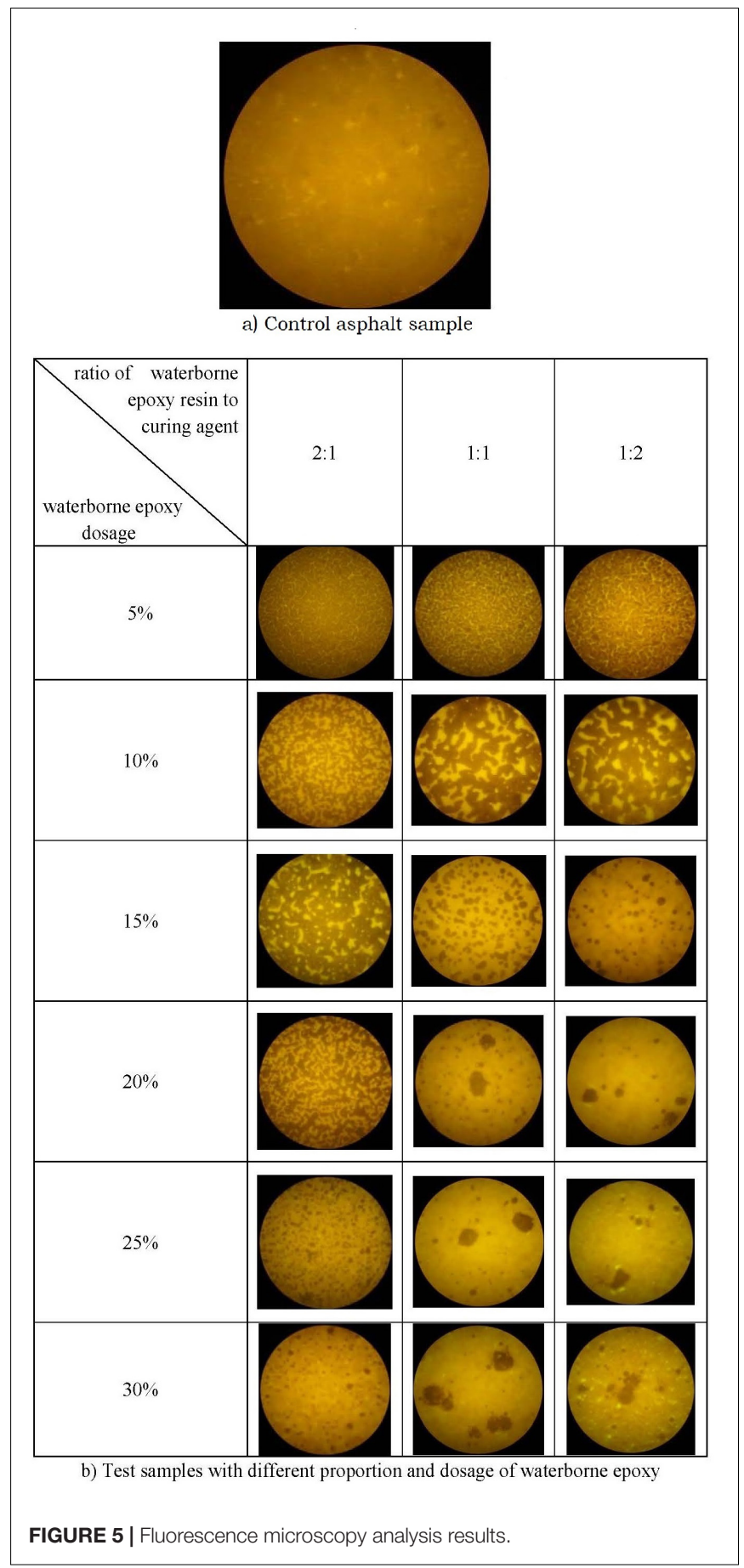

\section{RESULTS AND DISCUSSION}

\section{Asphalt Performance Test Results \\ Fluorescence Microscopy Analysis Results}

The fluorescence results for the asphalt control group without waterborne epoxy and the test groups with different proportions and dosages of waterborne epoxy are shown in Figures $5 \mathrm{~A}, \mathrm{~B}$, respectively.

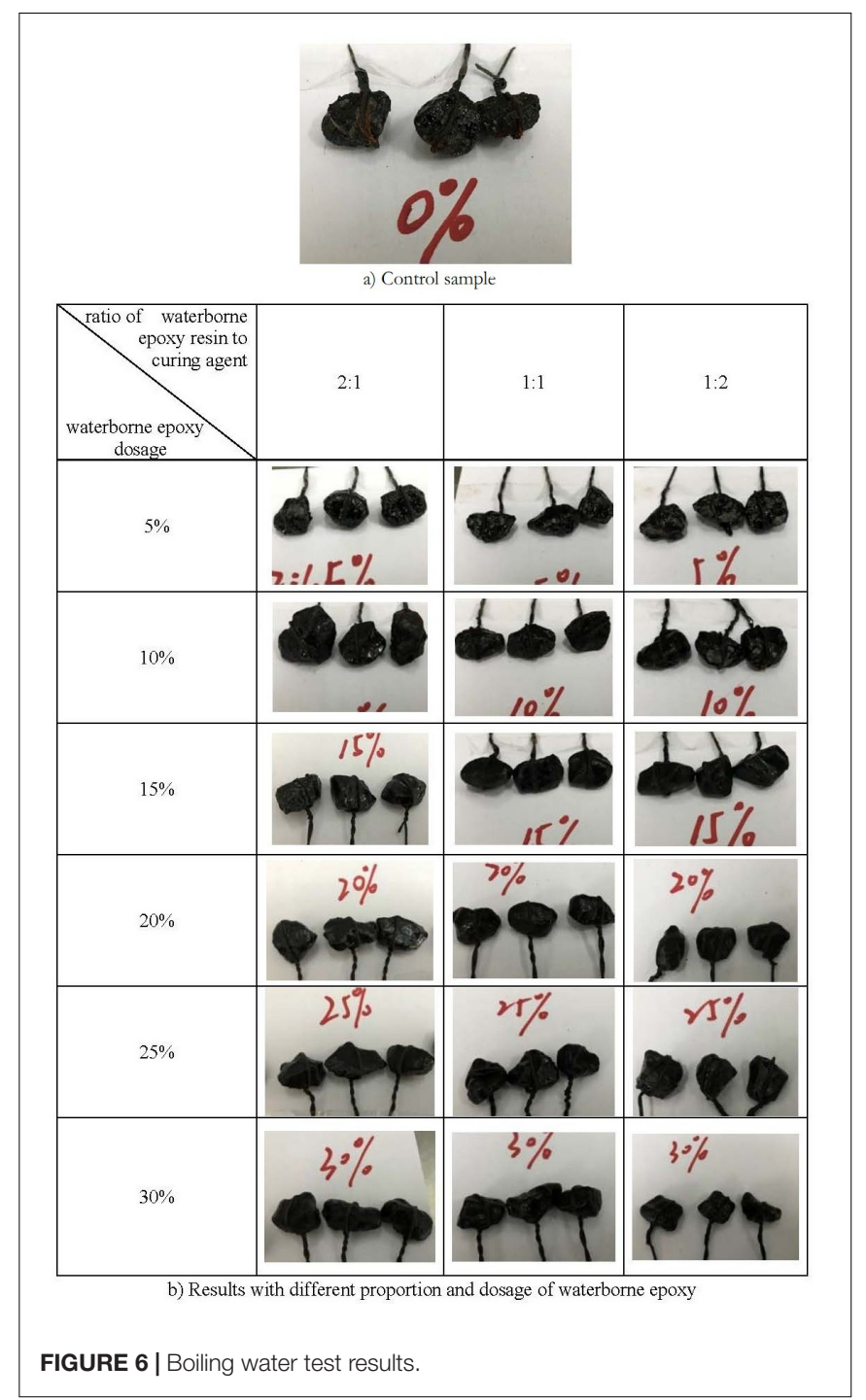

From Figure $\mathbf{5 A}$, it is seen that the control asphalt sample turned yellow under the fluorescence microscope. From Figure 5B, at a 5\% dosage of waterborne epoxy, all the waterborne epoxy resins are evenly distributed throughout the emulsified asphalt; as a result of the low content of waterborne epoxy resins, no network structure has formed. At a waterborne epoxy dosage of $15 \%$, the oleophilic content of the waterborne epoxy resin and the oil content of the asphalt molecules have attracted each other and gradually formed a network structure. At dosages greater than $20 \%$, the epoxy resin has agglomerated, resulting in unstable WEEA at ratios of $1: 1$ and 1:2. A comparison of the results by ratio indicate that the best distribution effect is reached at $2: 1$; thus, we recommend a dosage of waterborne epoxy of $30 \%$ with a ratio of 2:1.

\section{Boiling Water Test Results}

The water stabilities of the WEEA mixtures are primarily determined by the adhesive properties of the asphalts and the adhesion between the binder and aggregate. The adhesive grade 
TABLE 5 | Adhesion level results.

\begin{tabular}{|c|c|c|c|c|c|c|c|}
\hline \multirow[t]{2}{*}{ Adhesion level } & & \multicolumn{6}{|c|}{ Waterborne epoxy dosage/\% } \\
\hline & & 5 & 10 & 15 & 20 & 25 & 30 \\
\hline \multirow[t]{3}{*}{ Ratio of waterborne epoxy resin to curing agent } & $2: 1$ & 2 & 3 & 4 & 5 & 5 & 5 \\
\hline & $1: 1$ & 2 & 3 & 4 & 5 & 5 & 5 \\
\hline & $1: 2$ & 2 & 3 & 4 & 5 & 5 & 5 \\
\hline
\end{tabular}

TABLE 6 | Evaporative residue performance test results.

\begin{tabular}{|c|c|c|c|c|c|c|c|c|}
\hline \multirow[t]{2}{*}{ Test } & \multirow[t]{2}{*}{ Unit } & \multicolumn{7}{|c|}{ Waterborne epoxy dosage/\% } \\
\hline & & 0 & 5 & 10 & 15 & 20 & 25 & 30 \\
\hline Penetration at $25^{\circ} \mathrm{C}$ & $0.1 \mathrm{~mm}$ & 41 & 33.9 & 26.2 & 24.6 & 21.9 & 17.8 & 15.2 \\
\hline Ductility at $5^{\circ} \mathrm{C}$ & $\mathrm{cm}$ & 62 & 80 & 63.9 & 40.1 & 7.3 & - & - \\
\hline Softening point & ${ }^{\circ} \mathrm{C}$ & 80.3 & 80.7 & 82.1 & 84.1 & $>90$ & - & - \\
\hline
\end{tabular}

was determined according to the area of spalling, the higher the grade, the better the adhesion property. The results of the water boiling tests are shown in Figure 6, with the asphalt control group without waterborne epoxy resin results shown in Figure 6A, and the test group results shown in Figure 6B.

From Figure 6A, it is seen that a large post-testing area of asphalt spall has appeared on the surface of the aggregate, indicating poor adhesion to the aggregate in the emulsified asphalt without waterborne epoxy resin. From Figure 6B, it is seen that increasing the waterborne epoxy dosage decreases the spall area. At dosages greater than $15 \%$, no spalling is observed. For a given waterborne epoxy dosage, the ratio of waterborne epoxy resin emulsion to curing agent has little effect on the adhesion between asphalt and aggregate. The adhesion grade was evaluated by visual observation, with the results shown in Table 5 .

It is seen from Table 5 that, because the molecular chain of the waterborne epoxy resin has many polar groups that have strong adsorption capacities with aggregates, adding an appropriate amount of waterborne epoxy resin to the emulsified asphalt can improve the viscosity of the mixture and the adhesion between the asphalt and aggregates. Based on this, we recommend a dosage of waterborne epoxy of greater than $15 \%$.

\section{Evaporative Residue Performance Test Results}

Three indices-penetration, softening point, and ductility-were used to represent the viscosity and temperature sensitivity of the asphalts. The test results are listed in Table 6.

It is seen from the table that increasing the waterborne epoxy resin dosage changes each of these three indices significantly. As a result of the thermosetting property of the waterborne epoxy resin and the spatial network skeleton structure formed after the curing reaction, the evaporative residue gains a high strength and degree of temperature stability; indicating that enhancing the waterborne epoxy dosage makes the skeleton structure denser and the material harder. However, the penetration decreases sharply with dosage as a result of the increases in density and skeleton structure hardness. In the same manner, the ductility increases first and then decreases, while the softening point increases. At a waterborne epoxy dosage of $20 \%$, the softening point increases to above $90^{\circ} \mathrm{C}$.

\section{Mixture Performance Test Results}

The results of the predetermined anti-sliding performance, rutting, water stability, Cantabro, and low-temperature bending tests are listed in Table 7.

\section{Anti-sliding Performance Test Results}

It is seen from the table that the BPNs of the mixtures range from 77 to 82 and that all surface TDs are greater than $0.91 \mathrm{~mm}$. Under the Specification for Design of Highway Asphalt Pavement (2017; JTG D50-2017), the surface texture depth requirement of asphalt pavement in humid regions (in which the average annual rainfall is more than $1,000 \mathrm{~mm}$ ) is not less than $0.55 \mathrm{~mm}$. The anti-sliding performance of the OGFC-5 mixture meets this requirement. It is also seen that the waterborne epoxy resin has little effect on anti-sliding performance.

\section{Rutting Test Results}

It is seen from Table 7 that adding waterborne epoxy resin significantly improves the high-temperature stability of the mixture. The rutting depths of the mixture decreases, and the dynamic stability increases with increasing waterborne epoxy dosage. The dynamic stability of the mixture with $30 \%$ waterborne epoxy dosage is four times that of the mixture without water epoxy resin; this is because waterborne epoxy resin is a thermosetting resin that produces a post-curing skeleton structure that can improve the ability of the cementing material to resist loading deformation at high temperatures. Increasing the waterborne epoxy dosage improves the adhesion between aggregates and hardens the WEEA, leading to a mixture with a high level of hardness. In addition, the dynamic stability of the WEEA mixture is much higher than the specification requirements, indicating that the mixture has excellent hightemperature stability.

\section{Water Stability Test Results}

It is seen from Table 7 that, although the standard and immersion Marshall stabilities of the mixture increases with the waterborne 
TABLE 7 | Results of mixture performance tests.

\begin{tabular}{|c|c|c|c|c|c|c|}
\hline \multicolumn{3}{|c|}{ Test } & \multirow[t]{2}{*}{ Unit } & \multicolumn{3}{|c|}{ Waterborne epoxy dosage/\% } \\
\hline & & & & 0 & 15 & 30 \\
\hline \multirow[t]{2}{*}{ Anti-sliding performance tests } & Pendulum test & & - & 77.4 & 82.0 & 80.3 \\
\hline & Surface texture depth & & $\mathrm{mm}$ & 0.91 & 0.94 & 0.99 \\
\hline \multirow[t]{2}{*}{ Rutting test } & Rut depth & & $\mathrm{mm}$ & 1.432 & 1.245 & 0.963 \\
\hline & Dynamic stability & & times $/ \mathrm{mm}$ & 1,986 & 4,285 & 8,798 \\
\hline \multirow[t]{3}{*}{ Water stability test } & Standard Marshall stability & & $\mathrm{kN}$ & 6.10 & 7.20 & 15.20 \\
\hline & Immersion Marshall stability & & $\mathrm{kN}$ & 5.29 & 7.56 & 15.79 \\
\hline & Residual stability & & $\%$ & 86.7 & 105.0 & 103.9 \\
\hline Cantabro Test & Mass loss & & $\%$ & 23.4 & 20.1 & 16.0 \\
\hline \multirow[t]{6}{*}{ Low-temperature bending test } & Flexural tensile strength $R_{B}$ & $0^{\circ} \mathrm{C}$ & $\mathrm{MPa}$ & 0.728 & 1.898 & 4.516 \\
\hline & & $-10^{\circ} \mathrm{C}$ & & 1.014 & 2.204 & 4.727 \\
\hline & Maximum flexural tensile strain $\varepsilon_{B}$ & $0^{\circ} \mathrm{C}$ & $\mu \varepsilon$ & 1,314 & 1,556 & 2,130 \\
\hline & & $-10^{\circ} \mathrm{C}$ & & 1,441 & 1495 & 2,056 \\
\hline & Flexural stiffness modulus $s_{B}$ & $0^{\circ} \mathrm{C}$ & $\mathrm{MPa}$ & 554 & 1,220 & 2,120 \\
\hline & & $-10^{\circ} \mathrm{C}$ & & 704 & 1,474 & 2,299 \\
\hline
\end{tabular}

epoxy dosage, the increase obtained at a $15 \%$ dosage is not significant. However, increasing the dosage from 15 to $30 \%$ causes the Marshall stability to double. Looked at in conjunction with the results of the rutting and bending tests, these results might indicate that different loading methods lead to different results, and the unique loading method used by the Marshall test might not accurately reflect the strengthening effect of the WEEA on the material.

Compared with the mixture without WEEA, which has a residual stability of $86.7 \%$, the residual stabilities of the WEEA mixtures are significantly improved and, in some cases, exceed $100 \%$. This is the result of the hydration reaction of the cement continuing during the 48-h water bath maintenance, resulting in a cured waterborne epoxy product with a crosslinked structure that promotes the strength of the WEEA mixture.

\section{Cantabro Test Results}

From Table 7, it is seen that increasing the waterborne epoxy dosage decreases the mass loss in the mixture significantly. The appearances of the post-Cantabro test mixtures are shown in Figure 7. Increasing the waterborne epoxy dosage to $30 \%$ decreases the dispersion loss to $16 \%$, indicating that the addition of waterborne epoxy resin helps to improve the cohesiveness of the emulsified asphalt. This result is consistent with that of the boiling water test.

\section{Low-Temperature Bending Test Results}

From Table 7, it is seen that the use of WEEA significantly improves the flexural tensile strengths of the mixture. At the test temperature of $0^{\circ} \mathrm{C}$, the flexural tensile strength of the mixture with $30 \%$ waterborne epoxy is five times that of the mixture without waterborne epoxy; at $-10^{\circ} \mathrm{C}$ the flexural tensile strength is increased by a factor of nearly four. This result indicates that the WEEA significantly increases the strength of the asphalt mixture in proportion to the waterborne epoxy dosage. The maximum flexural tensile strain of the mixture also increases with the waterborne epoxy dosage. Although the

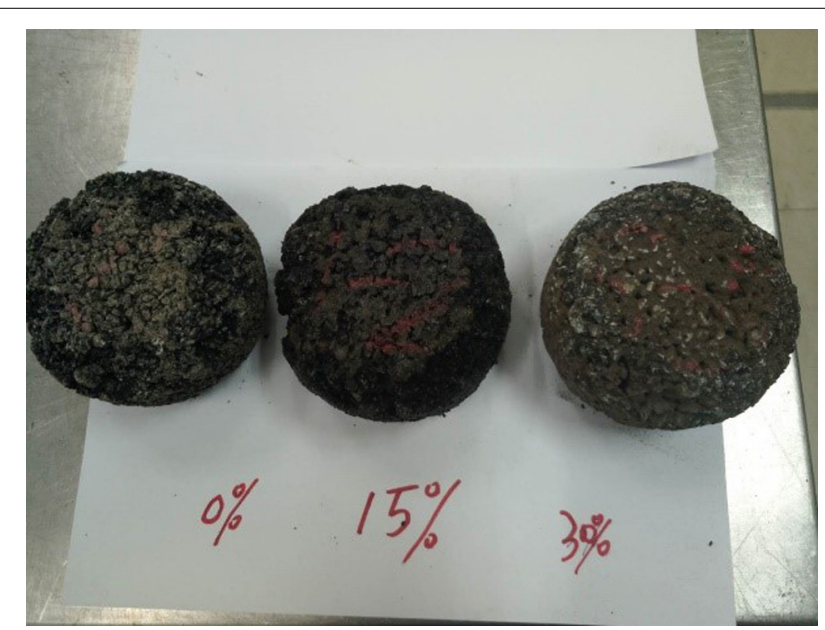

FIGURE 7 | Specimens after Cantabro Test.

increases in tensile strain are not as large as the increases in tensile strength, this result indicates that the WEEA has increased the deformation capacity of the material to some extent. The WEEA also increases the flexural stiffness modulus of the mixtures These results indicate that the network skeleton structure formed by WEEA increases the bonding effect and deformation ability of the asphalts, thereby enhancing the low-temperature performance of the asphalt mixture.

\section{CONCLUSION}

This study investigated the effects of using waterborne epoxy resin to modify emulsified asphalt. Specifically, the effects of waterborne epoxy resin dosage on the uniformity, compatibility, and adhesion of WEEA were studied. Following 
these assessments, the road performance of OGFC-5 WEEA mixtures were studied. The main conclusions are as follows:

The optimal ratio of the waterborne epoxy resin emulsion and curing agent was found to be $2: 1$, while the recommended dosage range of waterborne epoxy resin was determined to be 15$30 \%$. The Cantabro test results were consistent with those of the boiling water tests.

The OGFC-5 WEEA mixtures were shown to have relatively good pavement functional performance and high temperature performance. The TDs were all larger than $0.91 \mathrm{~mm}$ and the BPNs were all larger than 77.4. The residual stabilities of some of the WEEA mixtures exceeded $100 \%$, and the dynamic stabilities of the WEEA mixtures with 15 and 30\% waterborne epoxy dosages were measured at 4,285 and 8,798 times/mm, respectively.

The addition of WEEA significantly improved the lowtemperature performance of the mixture. Using 15 and 30\% waterborne epoxy resin dosages, the flexural tensile strengths at $-10^{\circ} \mathrm{C}$ were 2.204 and $4.727 \mathrm{MPa}$, respectively. The maximum flexural tensile strain and flexural stiffness modulus results indicate that the WEEA increased the deformation capacities of the materials.

\section{REFERENCES}

Anthonissen, J., Van den Bergh, W., and Braet, J. (2016). Review and environmental impact assessment of green technologies for base courses in bituminous pavements. Environ. Impact Asses. 60, 139-147. doi: 10.1016/j.eiar.2016. 04.005

Chávez-Valencia, L. E., Alonso, E., Manzano, A., Pérezb, J., Contreras, M. E., and Signoret, C. (2007). Improving the compressive strengths of cold-mix asphalt using asphalt emulsion modified by polyvinyl acetate. Constr. Build. Mater. 21, 583-589. doi: 10.1016/j.conbuildmat.2005. 07.017

Chen, R., Gong, J., Jiang, Y., Wang, Q., Xi, Z., and Xie, H. (2018). Halogenfree flame retarded cold-mix epoxy asphalt binders: rheological, thermal and mechanical characterization. Constr. Build. Mater. 186, 863-870. doi: 10.1016/j. conbuildmat.2018.08.018

Christina, P. (2019). Sustainability factors in pavement materials, design, and preservation strategies: a literature review. Constr. Build. Mater. 211, 539-555. doi: 10.1016/j.conbuildmat.2019.03.242

Field Test Methods of Subgrade and Pavement for Highway Engineering (2008). JTG E60. Beijing: China Communications Press.

Gu, Y., Tang, B., He, L., Yang, F., Wang, H., and Ling, J. (2019). Compatibility of cured phase-inversion waterborne epoxy resin emulsified asphalt. Constr. Build. Mater. 229:116942. doi: 10.1016/j.conbuildmat.2019.116942

Hamed, A. D., Abolfazl, M. M., Mohsen, K., and Bahar, S. (2019). Improving the resistance to moisture damage of cold mix asphalt modified by eco-friendly microbial carbonate precipitation (MCP). Constr. Build. Mater. 213, 131-141. doi: 10.1016/j.conbuildmat.2019.03.262

Hu, C., Zhao, J., Leng, Z., Partl, M. N., and Li, R. (2019). Laboratory evaluation of waterborne epoxy bitumen emulsion for pavement preventative maintenance application. Constr. Build. Mater. 197, 220-207. doi: 10.1016/j.conbuildmat. 2018.11.223

Jiang, J., Ni, F., Zheng, J., Han, Y., and Zhao, X. (2020). Improving the hightemperature performance of cold recycled mixtures by polymer-modified asphalt emulsion. Int. J. Pavement Eng. 21, 41-48. doi: 10.1080/10298436.2018. 1435882

Johann, E., and Juergen, H. (2004). Method for Fluorescence Microscopy, and Fluorescence Microscope. U.S. Patent No 6,806,953. Washington, DC: U.S. Patent and Trademark Office.

Khan, A., Redelius, P., and Kringos, N. (2016). Evaluation of adhesive properties of mineral-bitumen interfaces in cold asphalt mixtures. Constr. Build. Mater. 125, 1005-1021. doi: 10.1016/j.conbuildmat.2016.08.155

\section{DATA AVAILABILITY STATEMENT}

The datasets analyzed in this article are not publicly available. Requests to access the datasets should be directed to wukuanghuai@163.com.

\section{AUTHOR CONTRIBUTIONS}

$\mathrm{XC}$ and $\mathrm{KW}$ contributed to the conceptualization. $\mathrm{WH}$ contributed to the validation. XC and JL contributed to the investigation. $\mathrm{KW}$ and $\mathrm{JL}$ provided the resources. $\mathrm{XC}$ and $\mathrm{JL}$ curated the data. XC wrote and prepared the original draft. $\mathrm{WH}$ reviewed and edited the manuscript. KW supervised the study.

\section{FUNDING}

This work was financially supported by the National Natural Science Foundation of China (Grant Nos.: 51708144 and 51878193).

Kim, H. H., Mazumder, M., Lee, M.-S., and Lee, S.-J. (2019). Evaluation of highperformance asphalt binders modified with SBS, SIS, and GTR. Adv. Civ. Eng. 2019:2035954. doi: 10.1155/2019/2035954

Law, E. P., Diemont, S. A. W., and Toland, T. R. (2017). A sustainability comparison of green infrastructure interventions using emery evaluation. J. Clean. Prod. 145, 374-385. doi: 10.1016/j.jclepro.2016. 12.039

Liang, H., Wang, D., Wang, G., Li, D., Xu, C., and Liang, X. (2019). Numerical simulation and laboratory testing verification on the performance of an asphalt pavement seal coat with superficially permeating and solidifying properties. J. Test. Eval. 47, 4427-4451. doi: 10.1520/JTE2017 0625

Oruc, S., Celik, F., and Akpinar, M. V. (2007). Effect of cement on emulsified asphalt mixtures. J. Mater. Eng. Perform. 16, 578-583. doi: 10.1007/s11665-0079095-2

Oruc, S., Celik, F., and Aksoy, A. (2006). Performance of cement modified dense graded cold-mix asphalt and establishing mathematical model. Indian J. Eng. Mater. S. 13, 512-519. doi: 10.1109/TCAPT.2006.885844

Ouyang, J., Hu, L., Yang, W., and Han, B. (2019). Strength improvement additives for cement bitumen emulsion mixture. Constr. Build. Mater. 198, 456-464. doi: 10.1016/j.conbuildmat.2018.11.280

Ouyang, J., Zhao, J., and Tan, Y. (2018). Modeling mechanical properties of cement asphalt emulsion mortar with different asphalt to cement ratios and temperatures. J. Mater. Civ. Eng. 30:04018263. doi: 10.1061/(asce)mt.19435533.0002480

Pan, J., Du, S., Chang, R., Pei, Q., and Cui, D. (2015). Effect of emulsifier content on the rheological properties of asphalt emulsion residues. J. Appl. Polym. Sci. 2015:41806. doi: 10.1002/app.41806

Santos, J., Bressi, S., Cerezo, V., Lo Presti, D., and Dauvergne, M. (2018). Life cycle assessment of low temperature asphalt mixtures for road pavement surfaces: A comparative analysis. Resour. Conserv. Recycle 138, 283-297. doi: 10.1016/j. resconrec.2018.07.012

Shafii, M. A., Abdul Rahman, M. Y., and Ahmad, J. (2011). Polymer modified asphalt emulsion. Int. J. Civ. Environ. Eng. 11, 43-49. doi: 10.1016/j.jcis.2016. 07.063

Specification for Design of Highway Asphalt Pavement (2017). JTG D50. Beijing: China Communications Press.

Standard Test Methods of Bitumen and Mixtures for Highway Engineering (2011). JTG E20. Beijing: China Communications Press.

Test Methods of Aggregate for Highway Engineering (2005). JTG E42. Beijing: China Communications Press. 
Wang, J. (2015). Influence Factors of Structure-Formation and Properties of Waterborne Epoxy-Emulsified Asphalt. master's thesis, Chongqing Jiaotong University, Chongqing.

Wang, Y., Tan, Y., Guo, M., and Wang, L. (2017). Influence of emulsified asphalt on the mechanical property and microstructure of cement-stabilized gravel under freezing and thawing cycle conditions. Materials 10:504. doi: 10.3390/ ma10050504

Wang, Z., Shu, X., Rutherford, T., Huang, B., and Clarke, D. (2015). Effects of asphalt emulsion on properties of fresh cement emulsified asphalt mortar. Constr. Build. Mater. 75, 25-30. doi: 10.1016/j.conbuildmat.2014. 11.013

Wu, S., Wen, H., Zhang, W., Shen, S., Mohammad, L., Faheem, A., et al. (2019). Field performance of top-down fatigue cracking for warm mix asphalt pavements. Int. J. Pavement Eng. 20, 33-43. doi: 10.1080/10298436.2016. 1248204

Yang, G., Wang, C., Fu, H., Yan, Z., and Yin, W. (2019). Waterborne epoxy resinpolyurethane-emulsified asphalt: preparation and properties. J. Mater. Civ. Eng. 31:04019265. doi: 10.1061/(ASCE)MT.1943-5533.0002904
Yang, W., Ouyang, J., Meng, Y., Tang, T., Chen, J., and Han, B. (2020). Effect of superplasticizer and wetting agent on volumetric and mechanical properties of cold recycled mixture with asphalt emulsion. Adv. Mater. Sci. Eng. 5, 1-11. doi: $10.1155 / 2020 / 6251653$

Yu, D. (2018). Study on Waterborne Epoxy Resin Modified Emulsified Asphalt and the Performance of Mixture. master's thesis, Chongqing Jiaotong University, Chongqing.

Conflict of Interest: The authors declare that the research was conducted in the absence of any commercial or financial relationships that could be construed as a potential conflict of interest.

Copyright (c) 2020 Cai, Huang, Liang and Wu. This is an open-access article distributed under the terms of the Creative Commons Attribution License (CC BY). The use, distribution or reproduction in other forums is permitted, provided the original author(s) and the copyright owner(s) are credited and that the original publication in this journal is cited, in accordance with accepted academic practice. No use, distribution or reproduction is permitted which does not comply with these terms. 